\title{
Análise Experimental da Produção de Concreto de Alta Resistência (Car), Utilizando Materiais Encontrados na Região do Estado do Tocantins
}

\section{Experimental Analysis of the Production of High Strength Concrete (Hsc), Using Materials Found in the Region of Tocantins State}

Michael Vinicius Martins Caldeira', Adrielle Cardoso de Sousa².

\section{RESUMO}

Este trabalho tem como objetivo analisar o estudo no concreto convencional onde a ruptura ocorre geralmente na pasta de cimento, pois a aderência pasta-agregado é muito fraca, já no concreto de alta resistência (CAR) a mesma acontece no agregado, pois com adição de sílica e aditivo a zona de transição pasta-agregado fica bastante coesa. O concreto utilizado durante a pesquisa foi todo produzido com material da região do Estado do Tocantins, visando não somente a redução de custos, mas também sobre a ótica da otimização da mão de obra e melhor aproveitamento dos ambientes, assim tentar minimizar o consumo de material e consequentemente os impactos ambientas o emprego dos materiais utilizados encontrados na região, onde se tem um efeito significativo na resistência à compressão do CAR, chegando a ordem de $102 \mathrm{MPa}$ aos 28 dias e o sistema de cura térmica apresentou resultado $11,1 \%$ melhor que 0 sistema de cura úmida com 3 dias de cura.

Palavras-chave: Concreto de alta resistência (CAR); Estado do Tocantins; resistência à compressão

\section{ABSTRACT}

This work aims to analyze the study in the conventional concrete where the rupture usually occurs in the cement paste, because the paste-aggregate adhesion is very weak, already in the high resistance concrete (CAR) the same happens in the aggregate, because with addition of silica and additive the paste-aggregate transition zone is quite cohesive. The concrete used during the research was all produced with material from the state of Tocantins, aiming not only at reducing costs but also at optimizing the workforce and making better use of the environments, thus trying to minimize material consumption and consequently the environmental impacts the use of materials used in the region, where there is a significant effect on the compressive strength of the CAR, reaching the order of $102 \mathrm{MPa}$ at 28 days and the thermal curing system presented a result $11.1 \%$ better than the humid healing system with 3 days of healing.

Keywords: High-strength concrete (CAR); State of Tocantins; compressive strength 


\section{INTRODUÇÂOO}

Nas últimas décadas, os grandes avanços na tecnologia do concreto proporcionaram o surgimento dos concretos de alta resistência, cuja característica principal é a elevada resistência à compressão. Segundo MEHTA e MONTEIRO (2008) o concreto é definido como sendo de "alta resistência" apenas com base na resistência à compressão a uma dada idade. Na década de 1970, antes do advento dos superplastificantes, os concretos que apresentavam $40 \mathrm{MPa}$ ou mais de resistência à compressão aos 28 dias eram chamados de concretos de alta resistência, devido esta característica o diferenciavam do concreto convencional.

O Concreto de Alta Resistência (CAR) é um material que vem sendo largamente pesquisado e empregado em diversos países, como Estados Unidos, Canadá, França, Noruega, entre outros. No Brasil, o seu emprego é ainda limitado, tendo se desenvolvido quase exclusivamente nas grandes capitais, como São Paulo, Rio de Janeiro, Salvador, Porto Alegre, Florianópolis e Brasília, graças aos grupos de pesquisa concentrados nas universidades públicas (MENDES, 2002). Em Palmas - TO o emprego do concreto de alta resistência tem sido muito limitado na construção civil. No Estado do Tocantins há obras de grande porte que utilizaram concreto de alta resistência (CAR), como: A ponte Fernando Henrique Cardoso construída com CAR de $40 \mathrm{MPa}$ e a Ferrovia Norte-Sul em construção com CAR de $75 \mathrm{MPa}$.

\section{MATERIAIS E METODOS}

Com o intuito de caracterizar o concreto de alta resistência produzido com materiais encontrados na região, procedeu-se à realização do ensaio mecânico de resistência à compressão $\left(f_{c}\right)$.

A pesquisa foi realizada no Laboratório de Materiais de Construção Civil do Centro Universitário Luterano de Palmas, seguindo algumas etapas: levantamento bibliográfico, através de pesquisas e estudos anteriormente feitos para produção de concreto de alta resistência; seleção e coleta dos materiais necessários para realização do estudo, sendo que este foi armazenado no laboratório de materiais de construção do CEULP/ULBRA; caracterização dos materiais, através de ensaios específicos de cada material; estudo de dosagem, utilizando o método proposto por METHA e AITCIN (2008), com adaptações à realidade dos materiais utilizados na pesquisa; produção de traços preliminares para se determinar qual será o utilizado na pesquisa, posteriormente foi produzido os corpos de 
prova do CAR sendo os mesmos submetidos à cura térmica e úmida e por último, foram realizados os ensaios de resistência à compressão dos corpos-de-prova para se obter as resistências dos corpos de prova.

\subsection{SELEÇÃO E CARACTERIZAÇÃO DOS MATERIAIS}

Os materiais foram selecionados de acordo com a disponibilidade da região do Estado do Tocantins, os referidos materiais foram utilizados da maneira como fornecidos pelos fabricantes, sem alterações de suas características, exceto os agregados, que teve que ser feita a retirada de pó através de lavagem e o peneiramento para granulométrica necessária.

\subsubsection{CIMENTO}

O Cimento Portland (CP V - ARI) utilizado na pesquisa é composto de silicato de cálcio, alumínio e ferro, sulfato de cálcio e filler carbonático, com massa específica de 2,98 kg/dm³. Normatizado pela NBR 5733/1991, fornecido pela CIPLAN a empresa faz incentivo a pesquisas tecnológicas, o referido material foi selecionado por ter como característica principal a alta resistência inicial.

$\mathrm{Na}$ composição do concreto o cimento CP V - ARI foi utilizado na proporção de $60 \%$ em relação aos aglomerantes (sílica e escória), o mesmo foi depositado em local fechado em saco de plástico para a conservação de suas características iniciais.

\subsubsection{AGREGADOS MIÚDOS}

Foi utilizado como agregado miúdo a areia média, extraído pela empresa Mineração Capital na cidade de Palmas - TO. Este material foi lavado e secado em estufa a 300C para diminuir a umidade presente no mesmo, limitamos a areia como diâmetro máximo de 4,8 $\mathrm{mm}$ e com massa específica de $2,76 \mathrm{~kg} / \mathrm{dm}^{3}$.

\subsubsection{AGREGADOS GRAÚDOS}

Coletou-se o basalto extraído e processado com diâmetro máximo de 12,5mm e com massa específica de 2,36 kg/dm³ , fornecido pela Brita Sul, britador da cidade de Araguaína - TO. A utilização desde material com esta característica se mostra necessário pois através do estudo teórico demonstrou que no concreto de alta resistência a ruptura acontece no agregado graúdo, por ser a parte de menor resistência do referido material, desta forma foi adotado este material para produção do CAR. 


\subsubsection{SÍLICA ATIVA}

A Sílica Ativa foi adicionada ao concreto de alta resistência para melhorar as condições de porosidade e aderência na zona de transição da pasta/agregado e a resistência à abrasão. Nesta pesquisa foi utilizado o produto SILMIX - SíLICA ATIVA, segundo o manual do fabricante suas partículas têm o diâmetro médio de $0,2 \mu \mathrm{m}$, o que é muito menor que o diâmetro de um grão de cimento. Na Tabela 1, são apresentas as características físicas e químicas desde produto.

Tabela 1 - Características Físicas e Químicas SILMIX - SÍLICA ATIVA.

\begin{tabular}{|l|l|}
\hline \multicolumn{2}{|c|}{ CARACTERÍSTICAS FíSICAS E QUÍMICAS } \\
\hline Massa específica & $2.220 \mathrm{~kg} / \mathrm{m}^{3}$ \\
\hline Superfície específica & $20.000 \mathrm{~m}^{2} / \mathrm{kg}$ \\
\hline Formato de partícula & Esférico \\
\hline Diâmetro médio & $0,2 \mu \mathrm{m}$ \\
\hline Teor de SiO2 & Mín. $85 \%$ \\
\hline Umidade & Máx. $3 \%$ \\
\hline Equivalente Alcalino & Máx. $0,5 \%$ \\
\hline
\end{tabular}

\subsubsection{ESCÓRIA DE ALTO FORNO}

A Escória de Alto Forno foi fornecida pela empresa Estruturas de Aço Araguaia de Palmas -TO, usado pela empresa para jateamento de peças metálicas. Este material acrescido ao concreto ocupa os vazios do concreto e proporciona maior resistência a abrasão, tendo uma massa específica de $2,50 \mathrm{~kg} / \mathrm{dm}^{3}$.

\subsubsection{ADITIVO}

Adição de aditivo hiperplastificante (GLENIUM 51 - BASF) se fez necessário para uma melhor relação água/cimento diminuindo a quantidade de água e aumentando a trabalhabilidade do concreto no estado fresco, aumentando a resistência à compressão do concreto no estado endurecido, melhorando o acabamento do concreto e aumentando o módulo de elasticidade. Este produto é isento de cloretos e atende as prescrições da norma ASTM C 494, os dados técnicos são mostrados na Tabela 2. 
Tabela 2 - Dados Técnicos GLENIUM 51

\begin{tabular}{|l|l|}
\hline \multicolumn{2}{|c|}{ DADOS TÉCNICOS } \\
\hline Função Principal: & Superplastificante $3^{\text {a }}$ geração \\
\hline Base química: & Policarboxilatos \\
\hline Aspecto: & Liquido viscoso \\
\hline Cor: & Bege \\
\hline Densidade: & 1,067 a $1,107 \mathrm{~g} / \mathrm{cm}^{3}$ \\
\hline pH: & 5 a 7 \\
\hline Sólidos: & $28,531,5 \%$ \\
\hline Viscosidade: & 95 a $160 \mathrm{cps}$ \\
\hline
\end{tabular}

Segundo o catálogo do fabricante, o aditivo hiperplastificante GLENIUM 51, tem uma estrutura química diferenciada dos superplastificantes tradicionais, consiste de polímeros de éter carboxílico com largas cadeias laterais. No começo do processo de mistura iniciase o mecanismo de dispersão eletrostática, porém as cadeias laterais unidas à estrutura polimérica geram uma energia que estabiliza a capacidade de refração e dispersão das partículas de cimento. Com este processo obtém-se um concreto fluido com uma grande redução da quantidade de água

\subsection{7 ÁGUA DE AMASSAMENTO}

Utilizou-se na produção do CAR, água potável proveniente da rede de abastecimento do TO a SANEATINS.

\subsection{PROPORCIONAMENTO DOS MATERIAIS}

A proporção dos materiais utilizados nas misturas foi determinada com base do método proposto por METHA e AITCIN (2008), específico para concreto de alta resistência.

O método foi escolhido por apresentar facilidade na execução, planilhas que facilitam o proporcionamento dos materiais e a realização de ensaios preliminares com os materiais utilizados durante a pesquisa se fez necessário para ajuste do método escolhido.

A dosagem adotada foi determinada por meio de alguns parâmetros pré-fixados como a escolha dos aglomerantes, agregados miúdos e graúdos, adições e aditivo, a faixa de resistência de 50 a $100 \mathrm{MPa}$ e a relação água / aglomerante.

Por meio de ensaios feitos no laboratório de construção civil do Centro Universitário Luterano de Palmas - TO e informações fornecidas por fabricantes dos produtos utilizados na pesquisa fez-se a caracterização dos materiais como mostrado na Tabela 3. Sabendo 
que os referidos ensaios estão apresentados em planilhas e no laudo de cada material, bem como fichas técnicas dos fabricantes.

Tabela 3 - Características dos Materiais Utilizados na Produção do CAR

\begin{tabular}{|c|c|c|c|c|c|}
\hline MATERIAL & $\begin{array}{l}\text { IDENTIFICAÇÃO } \\
\text { /TIPO/ MARCA }\end{array}$ & $\begin{array}{c}\text { PROCEDÉNCIA / } \\
\text { FABRICANTE }\end{array}$ & $\begin{array}{c}\text { MASSA } \\
\text { ESPECÍFICA }\end{array}$ & $\begin{array}{l}\text { DIMENSÃO } \\
\text { MÁX }\end{array}$ & $\begin{array}{l}\text { MÓDULO } \\
\text { DE FINURA }\end{array}$ \\
\hline Cimento & CP-V ARI & $\begin{array}{c}\text { Ciplan } \\
\text { Palmas - TO }\end{array}$ & $2,95 \mathrm{~kg} / \mathrm{dm}^{3}$ & - & - \\
\hline Água & $\begin{array}{l}\text { Abastecimento } \\
\text { público }\end{array}$ & $\begin{array}{c}\text { Saneatins } \\
\text { Palmas - TO }\end{array}$ & - & - & - \\
\hline $\begin{array}{l}\text { Agregado } \\
\text { Miúdo }\end{array}$ & Areia Média & $\begin{array}{c}\text { Mineração Capital } \\
\text { Palmas - TO }\end{array}$ & $2,64 \mathrm{~kg} / \mathrm{dm}^{3}$ & $4,8 \mathrm{~mm}$ & 2,59 \\
\hline $\begin{array}{l}\text { Agregado } \\
\text { Graúdo }\end{array}$ & Basalto & $\begin{array}{c}\text { Brita Sul } \\
\text { Araguaina - TO }\end{array}$ & $2,69 \mathrm{~kg} / \mathrm{dm}^{3}$ & $12,5 \mathrm{~mm}$ & 3,48 \\
\hline Escória & Alto forno & $\begin{array}{c}\text { EAAL } \\
\text { Palmas - TO }\end{array}$ & $2,50 \mathrm{~kg} / \mathrm{dm}^{3}$ & $4,8 \mathrm{~mm}$ & - \\
\hline Sílica Ativa & SILMIX & $\begin{array}{c}\text { Impercia } \\
\text { Palmas - TO }\end{array}$ & $2,22 \mathrm{~kg} / \mathrm{dm}^{3}$ & $0,2 \mu \mathrm{m}$ & - \\
\hline Aditivo & $\begin{array}{c}\text { Hiperplastificante } \\
\text { GLENIUM } 51\end{array}$ & $\begin{array}{c}\text { Rivoli } \\
\text { Palmas - TO }\end{array}$ & & - & - \\
\hline
\end{tabular}

\subsection{DETERMINAÇÃO DO TRAÇO}

Foi determinada a proporção dos materiais a ser utilizada no estudo preliminar para se obter os resultados do ensaio de resistência a compressão com 3, 7 e 28 dias de cura (térmica e úmida), sendo que o $2^{\circ}$ traço foi determinado a partir dos primeiros resultados do $1^{\circ}$ traço, bem como o $3^{\text {o }}$ traço foi determinado da mesma forma, sendo usado o $2^{\circ}$ traço. Os dados referentes a determinação de cada traço apresentados na Tabela 4.

Tabela 4 - Proporcionamento do Material.

\begin{tabular}{|l|l|l|l|l|}
\hline MATERIAL & ESPECIFICAÇÃO & TRAÇO 01 & TRAÇO 02 & TRAÇO 03 \\
\hline Cimento & CP-V ARI & $10,0 \mathrm{~kg}$ & $10,3 \mathrm{~kg}$ & $10,8 \mathrm{~kg}$ \\
\hline Água & Saneatins & $2,0 \mathrm{lt}$ & $2,0 \mathrm{lt}$ & $2,3 \mathrm{lt}$ \\
\hline Agregado Miúdo & Areia Fina & $9,6 \mathrm{~kg}$ & $8,4 \mathrm{~kg}$ & $8,6 \mathrm{~kg}$ \\
\hline Agregado Graúdo & Basalto & $14,4 \mathrm{~kg}$ & $12,6 \mathrm{~kg}$ & $16,2 \mathrm{~kg}$ \\
\hline Escória & Alto Forno & $1,5 \mathrm{~kg}$ & $1,8 \mathrm{~kg}$ & $2,2 \mathrm{~kg}$ \\
\hline Ślica Ativa & Silmix & $1,5 \mathrm{~kg}$ & $1,2 \mathrm{~kg}$ & $1,1 \mathrm{~kg}$ \\
\hline Aditivo & Glenium 51 & $0,5 \mathrm{lt}$ & $0,5 \mathrm{lt}$ & $0,6 \mathrm{lt}$ \\
\hline Relação & Água / Cimento & 0,20 & 0,19 & 0,21 \\
\hline
\end{tabular}

Foram realizados três traços e os mesmos foram moldados em seis corpos de prova de cada um, os quais são suficientes para se analisar e fazer os comparativos necessários. 
Com a determinação da proporção dos materiais, iniciou o processo de separação do material necessário para produção do concreto, sendo este pesado e medido a quantidade pré-determinada.

\subsection{PRODUÇÃO DA MISTURA}

Foi utilizada uma betoneira de eixo inclinado com capacidade de 350 litros com motor monofásico de 2cv da marca Menegoti, para realização da mistura dos materiais na produção do concreto, foi molhado as paredes internas da betoneira com água antes de começar o processo de mistura, evitando que a água da mistura fosse absorvida pela parede anteriormente seca.

Desta forma, o material foi colocado na betoneira com velocidade constante, sendo primeiramente $100 \%$ do agregado graúdo (Basalto) britado com diâmetro máximo de 9,5 $\mathrm{mm}$ e adicionou-se $25 \%$ da água de amassamento para homogeneização do material.

Em seguida colocou-se $100 \%$ do cimento (CP-V ARI), mais $100 \%$ da sílica ativa (SILMIX) e $100 \%$ da escória de alto forno (previamente misturados), adicionando se $75 \%$ restantes da água de amassamento para não perder os materiais pulverulentos. Após um minuto de mistura adicionou-se $75 \%$ do aditivo (GLENIUM 51). Manteve-se na mesma velocidade por mais um minuto, em seguida adicionou-se 100\% do agregado miúdo (Areia Média).

Misturaram-se os materiais por mais dois minutos e deixa a betoneira parada por dois minutos, pois é o tempo necessário que o aditivo (Glenium 51) utilizado leva para reagir com os outros materiais. Foi colocado os $25 \%$ restantes do aditivo na mistura ligando a betoneira novamente por mais dois minutos finalizando assim a mistura dos materiais (Figura 3).

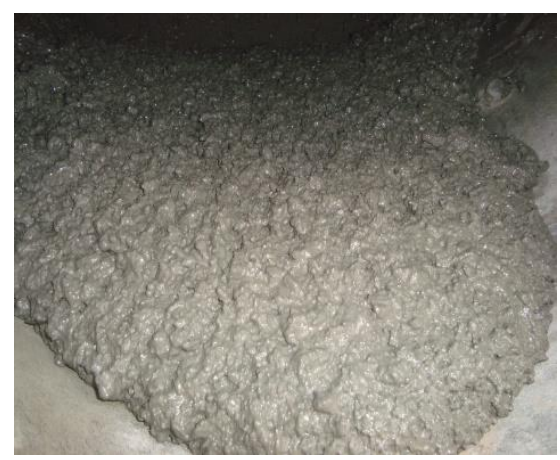

Figura 3 - Concreto no término do processo de produção

Deve-se observar que o tempo de mistura (10 minutos) para o concreto de alta resistência é superior ao tempo utilizado para concretos convencionais, devido ao comportamento 
tixotrópico que demanda maior energia de amassamento, sendo necessário misturar o concreto por mais tempo na betoneira, para assim obter a homogeneidade necessária (MENDES, 2002).

A tixotrópia é a propriedade que alguns materiais apresentam, quando no estado plástico, de adquirirem uma consistência gelatinosa quando deixados em repouso, mas ao serem solicitados ou agitados por esforços externos retornam a um estado fluido, viscoso.

Foram realizadas três moldagens com traços distintos, seguindo os mesmos procedimentos de mistura, sendo que o ambiente utilizado para dosagem estava sob condições de temperatura e umidade semelhantes devido ao horário e local realizado, de forma a evitar a interferência destes fatores nos resultados dos concretos. A programação de produção do CAR foi realizada conforme mostrado na Tabela 5.

Tabela 5 - Programação da moldagem dos traços.

\begin{tabular}{|c|c|}
\hline \multicolumn{2}{|c|}{$\begin{array}{c}\text { PROGRAMAÇÃO DE } \\
\text { MOLDAGEM DOS TRAÇOS }\end{array}$} \\
\hline TRAÇO & $\begin{array}{c}\text { DATA DE } \\
\text { MOLDAGEM }\end{array}$ \\
\hline 01 & $08 / 08 / 2012$ \\
\hline 02 & $18 / 08 / 2012$ \\
\hline 03 & $28 / 08 / 2012$ \\
\hline
\end{tabular}

\subsection{ENSAIO DE CONSISTÊNCIA}

Ao término da mistura (aproximadamente 10 minutos), realizou o ensaio de consistência pelo abatimento do tronco de cone, conhecido também como Slump Test (Figura 4). De acordo com a NBR NM 67/98: Concreto - Determinação da consistência pelo abatimento do tronco de cone. 


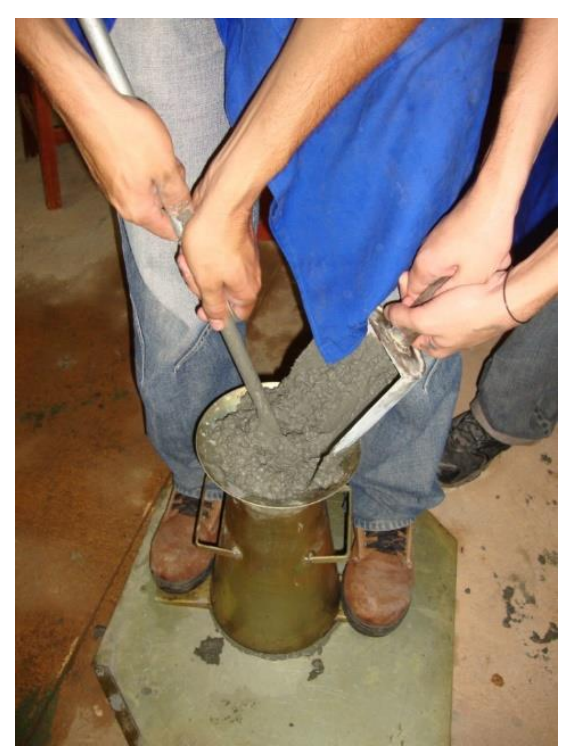

Figura 4 - Tronco de cone

\subsection{MOLDAGEM DOS CORPOS DE PROVA}

Após a realização do ensaio de abatimento, foram moldados quatro corpos de prova, para cada traço realizado, com dimensões de 100x200 mm, para realizar o ensaio de resistência a compressão (aos 3, 7 e 28 dias) seguindo a NBR 5739/94 Concreto - Ensaio de compressão de corpo de prova cilíndricos.

Deve-se salientar que antes de iniciar a mistura de concreto as formas metálicas utilizadas para fazer a moldagem dos corpos de prova já devem estar preparadas, sendo limpas, retirando toda a sujeira existente, em seguida passado o desmoldante (graxa) em toda à superfície que terá contato com o concreto no seu estado fresco, facilitando o desprendimento do concreto no estado endurecido.

Com o vibrador de imersão elétrico, utilizando uma agulha de $25 \mathrm{~mm}$ foi realizado o adensamentos dos corpos-de-prova (Figura 5). 


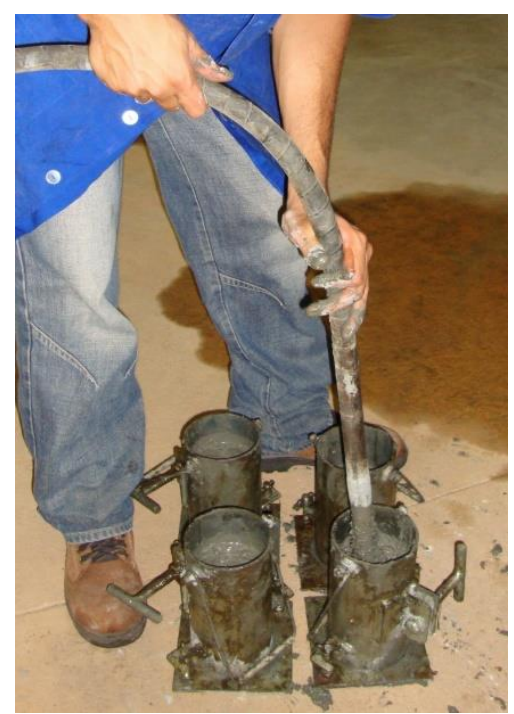

Figura 5 - Adensamento dos corpos-de-prova

Após a moldagem, os corpos-de-prova foram cobertos com plástico, evitando assim a perda de água do concreto, e mantidos em ambiente de laboratório aproximadamente 24 horas, sendo desmoldados, após este período, das formas metálicas.

\subsection{CURA DO CONCRETO}

Dos seis corpos de prova de cada traço, três foram submetidos a cura térmica por três dias, sendo estes colocados em um recipiente medindo $45 \times 45 \times 30,5 \mathrm{~cm}$ com capacidade de $0,062 m^{3}$ de água, os quais ficaram submersos até o topo de forma que o aquecedor elétrico de $220 \mathrm{v}$ fosse instalado. A temperatura mantida foi na média de $70^{\circ} \mathrm{C}$ com o volume de água adequado. Após os três dias de cura térmica os mesmos foram submetidos à cura úmida em uma temperatura de $24^{\circ} \mathrm{C}$ (Figura 7)

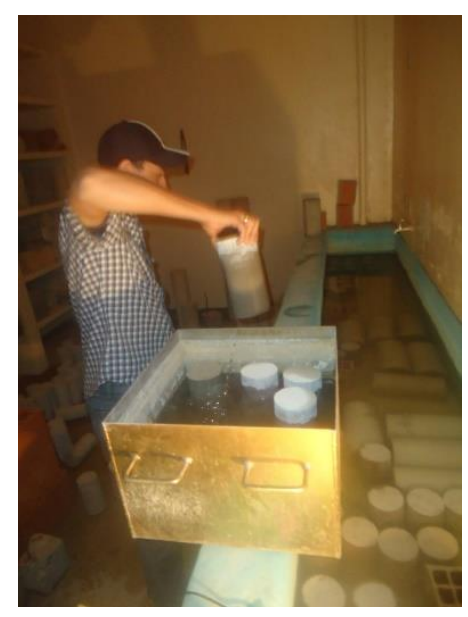

Figura 7 - Recipiente com corpos de prova submetidos a cura térmica. 
Os outros três corpos de prova restantes de cada traço foram submetidos diretamente a cura úmida, sendo colocados em local apropriado em ambiente de laboratório com a temperatura controlada de $24^{\circ} \mathrm{C}$ (Figura 8 ).

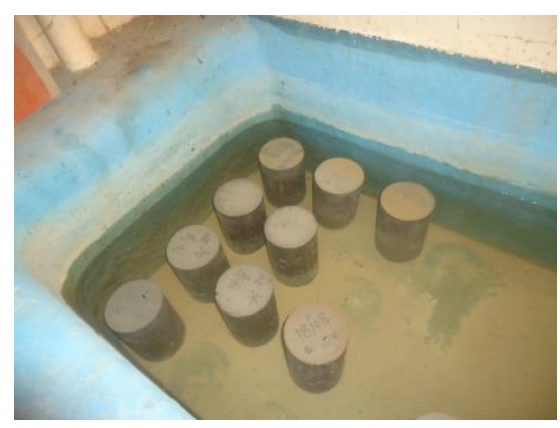

Figura 8 - Tanque com corpos de prova submetidos a cura úmida.

\subsection{CAPEAMENTO DOS CORPOS DE PROVA}

Para realização desde ensaio, tiveram que ser capeado os corpos de prova, pois a superfície superior dos mesmos fica irregular (Figura 9).

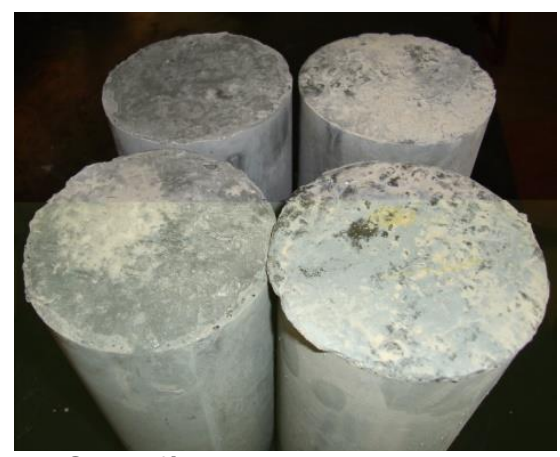

Figura 9 - Superfície superior dos corpos de prova

Para esta regularização da superfície dos corpos-de-prova foram submetidos ao processo de corte utilizando uma serra mármore de bancada.

2.8.1 Com a superfície totalmente regular ao término desde processo, os corpos-de-prova ficam prontos para serem submetidos ao ensaio de resistência à compressão. 


\subsection{ENSAIO DE RESISTÊNCIA À COMPRESSÃO}

Os ensaios de resistência à compressão $\left(f_{c}\right)$ foram realizados de acordo o método proposto pela NBR-5730/94.

Na Tabela 1.6, é mostrada a programação dos ensaios de ruptura dos corpos-de-prova, de acordo com a data de moldagem.

Tabela 5 - Programação de Ensaios de Ruptura

\begin{tabular}{|l|l|l|l|l|l|l|l|}
\hline \multicolumn{7}{|c|}{ PROGRAMAÇÃO DE ENSAIOS } \\
\hline \multicolumn{2}{|c|}{$\begin{array}{c}\text { Resistência à } \\
\text { Compressão }\end{array}$} & \multicolumn{2}{c|}{3 DIAS DE CURA } & \multicolumn{2}{c|}{7 DIAS DE CURA } & \multicolumn{2}{c|}{28 DIAS DE CURA } \\
\hline Traço & $\begin{array}{l}\text { Data da } \\
\text { Moldagem }\end{array}$ & Térmica & Úmida & Térmica & Úmida & Térmica & Úmida \\
\hline 01 & $08 / 08 / 12$ & $11 / 08 / 12$ & $11 / 08 / 12$ & $15 / 08 / 12$ & $15 / 08 / 12$ & $06 / 08 / 12$ & $06 / 08 / 12$ \\
\hline 02 & $18 / 08 / 12$ & $21 / 08 / 12$ & $21 / 08 / 12$ & $25 / 08 / 12$ & $25 / 08 / 12$ & $16 / 09 / 12$ & $16 / 09 / 12$ \\
\hline 03 & $28 / 08 / 12$ & $31 / 08 / 12$ & $31 / 08 / 12$ & $04 / 09 / 12$ & $04 / 09 / 12$ & $26 / 09 / 12$ & $26 / 09 / 12$ \\
\hline
\end{tabular}

Foi utilizada a prensa EMIC (Figura 10), com capacidade de $2000 \mathrm{KN}$, na realização dos ensaios, aplicando uma carga constante de 1,2. A ruptura dos corpos de prova é necessária para a obtenção dos resultados de resistência à compressão axial do concreto, seguindo os procedimentos da NBR 5739 (ABNT, 1994b).

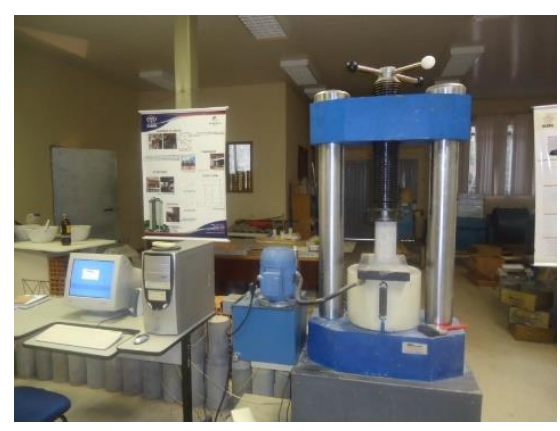

Figura 10 - Ensaio de Resistência à Compressão

\section{RESULTADOS}

\subsection{Slump Test}

Os resultados obtidos através dos ensaios de abatimento do tronco de cone estão apresentados na Tabela 6. Quanto maior o valor encontrado durante o Slump Test possibilita uma maior maleabilidade do concreto. Assim os valores obtidos durante o teste nos três traços demonstraram-se satisfatórios, podendo ser empregados em centrais de usinas de concreto. 
Tabela 6 - Tabela de Slump

\begin{tabular}{|c|c|c|}
\hline TRAÇO & RELAÇÃO ÁGUA/CIMENTO & SLUMP (mm) \\
\hline 01 & 0,20 & 205 \\
\hline 02 & 0,19 & 195 \\
\hline 03 & 0,21 & 210 \\
\hline
\end{tabular}

\subsection{ENSAIOS DE RESISTÊNCIA À COMPRESSÃO}

A Tabela 7 apresenta os valores obtidos com os resultados dos ensaios realizados conforme programação apresentada na Tabela 5.

Tabela 7 - Resultados de ruptura dos corpos de prova.

\begin{tabular}{|c|c|c|c|c|c|c|c|}
\hline \multicolumn{7}{|c|}{ ENSAIOS DE RESISTÊNCIA À COMPRESSÃO } \\
\hline \multicolumn{2}{|c|}{$\begin{array}{c}\text { Resistência à } \\
\text { Compressão }\end{array}$} & \multicolumn{2}{|c|}{3 DIAS DE CURA } & \multicolumn{2}{|c|}{7 DIAS DE CURA } & \multicolumn{2}{c|}{28 DIAS DE CURA } \\
\hline Traço & $\begin{array}{c}\text { Data da } \\
\text { Moldagem }\end{array}$ & Térmica & Úmida & Térmica & Úmida & Térmica & Úmida \\
\hline 01 & $08 / 08 / 12$ & $73 \mathrm{MPa}$ & $49 \mathrm{MPa}$ & $74 \mathrm{MPa}$ & $73 \mathrm{MPa}$ & $73 \mathrm{MPa}$ & $91 \mathrm{MPa}$ \\
\hline 02 & $18 / 08 / 12$ & $77 \mathrm{MPa}$ & $68 \mathrm{MPa}$ & $86 \mathrm{MPa}$ & $72 \mathrm{MPa}$ & $99 \mathrm{MPa}$ & $74 \mathrm{MPa}$ \\
\hline 03 & $28 / 08 / 12$ & $72 \mathrm{MPa}$ & $60 \mathrm{MPa}$ & $69 \mathrm{MPa}$ & $51 \mathrm{MPa}$ & $65 \mathrm{MPa}$ & $43 \mathrm{MPa}$ \\
\hline
\end{tabular}

Com os resultados obtidos dos traços preliminares mostrados na Tabela 7, foi escolhido 0 Traço 02 para dar continuidade ao estudo experimental, por apresentar os melhores resultados quanto ao ensaio de resistência à compressão axial, chegando a $99 \mathrm{MPa}$ aos 28 dias de cura, desta forma foi realizado a moldagem dos copos de prova desde traço determinado através do pré-dimensionamento, onde foram retirados 06 (seis) corpos-deprova para cada idade sendo três para cura térmica e três para cura úmida, totalizando dezoito corpos de prova. Como mostrado na programação apresentada na Tabela 8. 
Tabela 8 - Programação de Ensaios.

\begin{tabular}{|l|l|l|l|l|}
\hline \multicolumn{5}{|c|}{ PROGRAMAÇÃO DE ENSAIOS } \\
\hline Moldagem do Traço & Data do Ensaio de Ruptura \\
\hline CP & Data & 3 DIAS & 7 DIAS & 28 DIAS \\
\hline 01 & $22 / 09 / 2012$ & $26 / 09 / 2012$ & $29 / 09 / 2012$ & $20 / 10 / 2012$ \\
\hline 02 & $22 / 09 / 2012$ & $26 / 09 / 2012$ & $29 / 09 / 2012$ & $20 / 10 / 2012$ \\
\hline 03 & $22 / 09 / 2012$ & $26 / 09 / 2012$ & $29 / 09 / 2012$ & $20 / 10 / 2012$ \\
\hline
\end{tabular}

A Tabela 9 apresenta os valores obtidos seguindo a programação previamente estabelecida.

Tabela 9 - Resultados de Ruptura CP (Cura Úmida)

\begin{tabular}{|c|c|c|c|c|}
\hline \multicolumn{5}{|c|}{$\begin{array}{c}\text { RESISTÊNCIAS DOS CORPOS DE PROVA SUBMETIDOS A CURA } \\
\text { ÚMIDA (MPa) }\end{array}$} \\
\hline $\mathrm{CP}$ & $\begin{array}{l}\text { Data da } \\
\text { Moldagem }\end{array}$ & 3 Dias & 7 Dias & 28 Dias \\
\hline 01 & 22/09/2012 & 81.6 & 82.9 & 97.8 \\
\hline 02 & 22/09/2012 & 79.5 & 91.4 & 101.6 \\
\hline 03 & 22/09/2012 & 78.8 & 88.9 & 101.7 \\
\hline \multicolumn{2}{|c|}{ MÉDIA } & 80.0 & 87.7 & 100.4 \\
\hline
\end{tabular}

Como pode se observar, com 3 dias de cura o concreto chegou a 79,7\% da resistência apresentada com 28 dias de cura, o gráfico abaixo (Gráfico 1) mostra a curva de ganho de resistência do concreto após 3,7 e 28 dias de cura úmida.

Gráfico 1 - Gráfico da Resistência dos corpos de prova submetidos à Cura Úmida

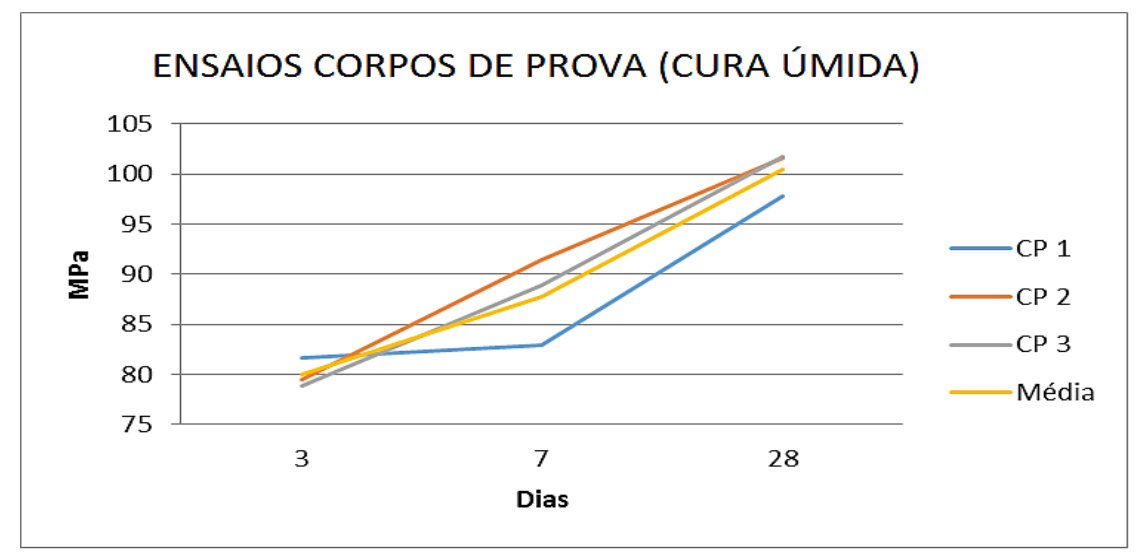


Da mesma forma foi realizado o ensaio de resistência com os CP de cura térmica, mostrado na Tabela 10.

Tabela 1.10: Resultados de Ruptura CP (Cura Térmica)

\begin{tabular}{|c|c|c|c|c|}
\hline \multicolumn{5}{|c|}{$\begin{array}{l}\text { RESISTÊNCIAS DOS CORPOS DE PROVA } \\
\text { SUBMETIDOS A CURA TÉRMICA (MPa) }\end{array}$} \\
\hline $\mathrm{CP}$ & $\begin{array}{l}\text { Data da } \\
\text { Moldagem }\end{array}$ & 3 Dias & 7 Dias & 28 Dias \\
\hline 01 & 22/09/2012 & 90.4 & 93.5 & 101.9 \\
\hline 02 & 22/09/2012 & 90.0 & 95.7 & 103.7 \\
\hline 03 & 22/09/2012 & 87.0 & 96.3 & 101.9 \\
\hline \multicolumn{2}{|c|}{ MÉDIA (MPa) } & 89.1 & 95.2 & 102.5 \\
\hline
\end{tabular}

Os resultados do traço apresentado No Gráfico 2, apresentou os melhores resultados quando comparados com os da cura úmida, tendo 11,3\% maior resistência com 3 dias de cura, já com 28 dias de cura não apresentou diferença significativa.

Gráfico 2 - Gráfico da Resistência dos corpos de prova submetidos à Cura Térmica

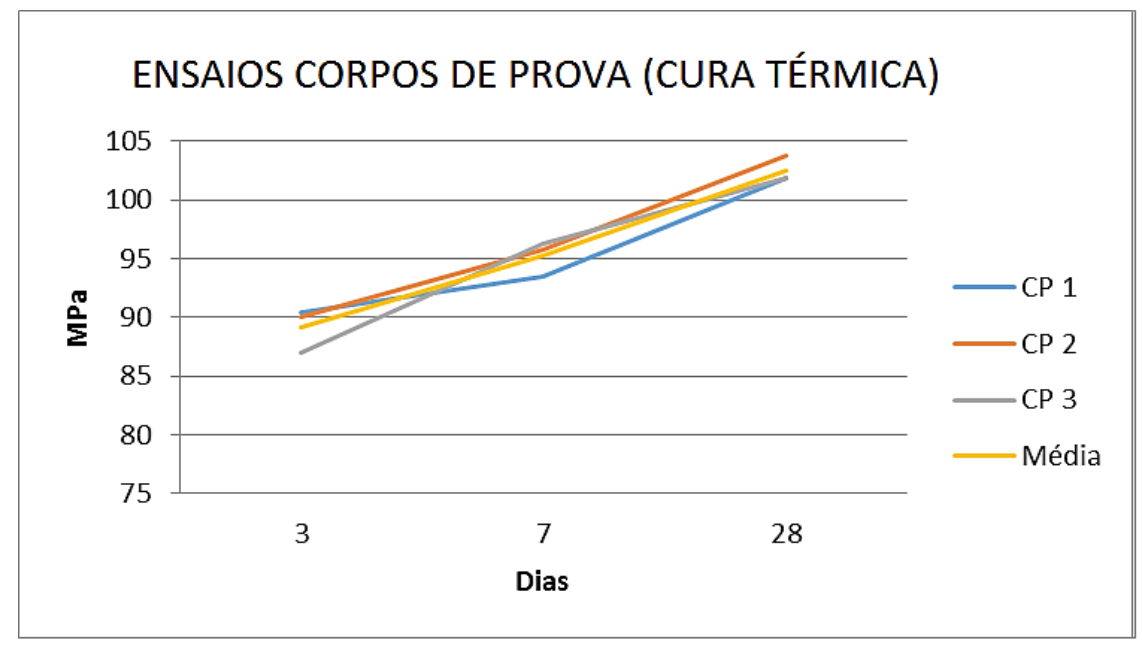

\section{CONSIDERAÇÖES FINAIS}

De acordo com a metodologia empregada e os resultados obtidos pode-se afirmar que o material encontrado na região do Estado do Tocantins, o qual foi utilizado durante a elaboração da pesquisa mostrou-se adequado para a produção do concreto de alta resistência.

Assim, foi verificado nesse trabalho, que o sistema de cura térmica obteve um melhor desempenho, dado no terceiro dia de cura apresentou uma maior resistência quando 
comparado ao corpo de prova com os mesmos três dias que foi submetido a cura úmida. Já com os corpos de prova com 28 dias não apresentou diferença significativa entre a cura térmica e a cura úmida.

Os corpos de prova realizado seguindo o traço 2, no qual foi escolhido para dar continuidade a pesquisa, quando analisado a sua resistência mostrou-se satisfatório obtendo resultados da ordem de $100 \mathrm{MPa}$ com 28 dias de cura.

Por fim, mostra-se que a resistência obtida durante a compressão axial, com apenas três dias, atingiu $80 \%$ na cura úmida e $87 \%$ na térmica, quando comparada a sua resistência apresentada aos 28 dias.

\section{REFERÉNCIAS}

ALVES, D. A. Manual de Tecnologia do Concreto. UFG, Goiânia, 1982.

CAMARINI, G.; CINCOTTO, M. A. Efeito da Cura Térmica na Resistência de Argamassa de Cimento Portland Comum e de Alto - Forno. Escola Politécnica, São Paulo, 1995.

GIAMMUSSO, S. E. Manual do Concreto. PINI, 1992.

ISAIA, G. C. Concreto: Ciência e Tecnologia Vol. I e II. 1ed. São Paulo, IBRACON, 2011.

ISAIA, G. C. Concreto para Infraestrutura Sustentável 1ed. São Paulo, IBRACON, 2011.

LEONHARDT, F.; MÖNNIG E. Construções de Concreto: Princípios básicos do dimensionamento de estruturas de concreto armado. 1ed, Rio de Janeiro, INTERCIÊNCIA, 1982.

MEHTA, P. K.; MONTEIRO, P. J. M. Concreto: Microestruturas, Propriedades e Materiais. 3ed, São Paulo, IBRACON, 2008.

MENDES, S. D. S. Estudo experimental de concreto de alto desempenho utilizando agregados graúdos disponíveis na região metropolitana de Curitiba. Curitiba, UFPR, 2002.

NBR 6118: Projeto de Estruturas de Concreto - Procedimento, Rio de Janeiro, 2003.

NBR 14724: Informação e documentação - Trabalhos acadêmicos - Apresentação, Rio de Janeiro, 2005.

NBR 10520: Informação e documentação - Citações em Documentos - Apresentação, Rio de Janeiro, 2002.

NBR 6023: Informação e documentação - Referências - Elaboração, Rio de Janeiro, 2002. 
NBR 5738: Moldagem e cura de corpos-de-prova cilíndricos ou prismáticos de concreto, Rio de Janeiro, 1994.

NBR 5739: Concreto: ensaio de compressão de corpos-de-prova cilíndricos de concreto - Método de ensaio, Rio de Janeiro, 1994.

NBR 8522: Concreto: Curva Tensão Deformação, Rio de Janeiro, 2003.

NBR NM 67: Concreto - Determinação da consistência pelo abatimento do tronco de cone, Rio de Janeiro, 1998.

PINTO, V. C.; SANTANA, M. J.; SOUZA, P. S. Propriedades mecânicas de concretos submetidos a diferentes tipos de cura, 51 Congresso Brasileira do Concreto. Curitiba, IBRACON, 2009.

QUEIROGA, M. V. M. Concreto de Alta Resistência: Propriedades, características e Experimentações. 1ed, São Paulo, ULBRA, 2000.

RIBEIRO, F. H. M.; ARANTE, J.; CASSOL, V. Avaliação da influência da cinza de casca de arroz produzida no Estado do Tocantins nas propriedades do concreto nos estados plástico e endurecido. 47 ${ }^{\circ}$ Congresso Brasileiro do Concreto. Recife, IBRACON, 2005

SÁNCHEZ, E. S. Nova Normalização Brasileira para o Concreto Estrutural. 1ed, Rio de Janeiro, INTERCIÊNCIA, 1999.

SILVA, A. S. R.; FERREIRA, E. A. M. Avaliação de parâmetros de desempenho de concreto contendo agregado graúdo de escória de ferro-cromo. 47 Congresso Brasileiro do Concreto, Recife, IBRACON, 1999.

SOUZA, C. M. D.; RIPPER, T. Patologia, recuperação e reforço de estruturas de concreto. 1ed, São Paulo, PINI, 1998. 